\title{
Redefining Serum PSA Cut-off in Indian Population to Avoid Unnecessary Biopsies - A Descriptive Study
}

Javangula Venkata Surya Prakash

Stanley Medical College

Thiruvarul PV

Stanley Medical College

Vetrichandar Sattanathan

Stanley Medical College

Krishnan Vembu Arasi

Stanley Medical College

ArunKumar Paranjothi

Stanley Medical College

ArunKumar Paranjothi

Stanley Medical College

Somanatha Sharma ( $\nabla$ spideysoms@gmail.com )

Stanley Medical College https://orcid.org/0000-0002-4876-0389

\section{Research Article}

Keywords: Serum PSA, Cut-off, india, ca prostate, prostate, cancer

Posted Date: September 16th, 2021

DOI: https://doi.org/10.21203/rs.3.rs-864534/v1

License: (c) (i) This work is licensed under a Creative Commons Attribution 4.0 International License.

Read Full License 


\section{Abstract}

INTRODUCTION:

Prostate cancer is the second most common cancer diagnosed in men with an estimated 1.2 million diagnoses worldwide. The incidence of Prostate cancer is higher in western countries and low in Asian countries. The need for prostate biopsy is based on PSA levels. The general cut off PSA value for the Indian population is $4.0 \mathrm{ng} / \mathrm{mL}$. The reported cancer detection rate of TRUS-guided biopsies is around 30 percent in western countries and lesser in Asian countries, including India, particularly for serum PSA values less than $20 \mathrm{ng} / \mathrm{mL}$ indicating that many of the Indian patients are subjected to unnecessary biopsy which adds up to distress to these patients.

PURPOSE:

To determine the cancer detection rate of TRUS-guided prostate biopsy in the Indian population at different serum Prostate-Specific Antigen levels and determine a PSA cut-off level to avoid unnecessary biopsies.

\section{MATERIALS AND METHODS:}

All symptomatic patients who underwent TRUS guided biopsy for raised serum PSA levels between 4 - 20 $\mathrm{ng} / \mathrm{mL}$ were included. The patients were categorized into four groups corresponding to the PSA levels ranging between 4-6 ng/mL, 6- $8 \mathrm{ng} / \mathrm{mL}$, 8-10 ng/mL, and 10-20 ng/mL respectively, and cancer detection rate in each group were statistically analyzed.

\section{RESULTS:}

The sensitivity, specificity, and positive predictive value of TRUS guided biopsy are $75 \%, 95 \%$, and $98 \%$ respectively in our study. The overall cancer detection rate of TRUS biopsy in our series was $18.4 \%$. The PSA cut-off to do biopsy was derived by ROC curve as $8.9 \mathrm{ng} / \mathrm{ml}$ for all the men.

CONCLUSION:

The PSA cut-off of $4.0 \mathrm{ng} / \mathrm{mL}$ is currently used as an indication for biopsy among men of all ages in the Indian population. We recommend a raise in cut-off to $8.9 \mathrm{ng} / \mathrm{mL}$ to avoid unnecessary TRUSguided biopsies in the Indian population.

\section{Background:}

Prostate cancer is the second most commonly diagnosed cancer in men worldwide with an estimated 1.1 million diagnoses accounting for $15 \%$ of cancers diagnosed [1]. The incidence of autopsy detected Prostate Cancer (PCa) is roughly equal worldwide. However, there is a wide variation in the incidence of 
PCa diagnosis between geographical areas being higher in Australia, North America and Europe countries mostly due to the use of prostate-specific antigen (PSA) screening tests and the aging population. The incidence of is low in the Asian countries[2]. India is the second most populous country in the world with an estimated population of 51 million men above 60 years of age [3]. Although the incidence of prostate cancer is increasing in the developed world, it remains under-diagnosed in the developing world where it often presents late. Serum Prostate specific antigen (PSA) is used as a diagnostic as well as prognostic marker of PCa since its discovery. biopsy of the prostate forms the cornerstone in establishing the diagnosis of PCa. The cancer detection rates in India have been lower than the western world for serum PSA values that fall in the grey zone: $4-10 \mathrm{ng} / \mathrm{dL}$, implying that PSA levels vary with race and ethnicity. However, a strict PSA screening protocol has not been adopted in India owing to the lower incidence of PCa. The reported cancer detection rate of Trans-Rectal Ultrasonography (TRUS) guided prostate biopsies ranges between 30-40 percent in western countries and about 20 percent in Asian countries, including India ${ }^{2}$. This study was conducted to find out the cancer detection rate of TRUS guided prostate biopsy in Indian population in the standard grey zone levels of serum PSA and to re-evaluate the need for TRUS guided biopsies in the same setting to curb the burden of prostate biopsies in Indian population. MEASUREMENT of serum prostate-specific antigen (PSA) is widely used as an aid in the early detection of prostate cancer. ${ }^{1} \mathrm{~A}$ limitation of PSA testing has been its relative lack of specificity within the 4.0 - to $10.0-\mathrm{ng} / \mathrm{mL}$ range, a diagnostic gray zone in which prostate cancer is present in only $25 \%$ of patients. Most patients with prostate cancer and a PSA level less than $10.0 \mathrm{ng} / \mathrm{mL}$ have early-stage disease, whereas more than half of the patients with PSA levels above $10.0 \mathrm{ng} / \mathrm{mL}$ have advanced disease. ${ }^{1}$ Thus, the detection of prostate cancer in its potentially curable stages requires the use of low PSA cutoffs for screening, which leads to many unnecessary biopsies.

\section{Materials And Methods:}

The study population included a total of 125 men between 45 to 80 years with elevated serum PSA in a single institution. All patients who were subjected to TRUS and TRUS guided biopsy for serum PSA levels between $4 \mathrm{ng} / \mathrm{mL}$ and $20 \mathrm{ng} / \mathrm{mL}$, irrespective of digital rectal examination (DRE) findings from August 2017 to August 2020 were included. Patients with recent history of urinary tract infection, urinary retention, per-urethral instrumentation or catheterisation, serum PSA levels of more than $20 \mathrm{ng} / \mathrm{dL}$ and patients who were taking 5-alpha reductase inhibitor were excluded from this study. Final HPE report suggestive of chronic prostatitis were also excluded from this study.

Serum PSA levels, TRUS findings and TRUS guided biopsy data were prospectively collected, on a standardised proforma at the time of biopsy and combined with the histological findings. Only patients with complete data sets were included in the study. Clinical parameters included patient demographics including age, volume of prostate, Total PSA value, and findings on TRUS.

Absolute PSA values were recorded and subsequently subdivided for the purposes of analyses into four groups: $A, B, C$ and $D$ corresponding to the PSA levels ranging between $4-6 \mathrm{ng} / \mathrm{mL}, 6-8 \mathrm{ng} / \mathrm{mL}, 8-10$ 
$\mathrm{ng} / \mathrm{mL}$, and $10-20 \mathrm{ng} / \mathrm{mL}$ respectively and cancer detection rate in each group were statistically analysed.

TRUS was performed using a Mindray DP-50 diagnostic ultrasound machine with a 7.5-MHz transrectal probe. Informed consent was obtained. All patients were given tablet bisacodyl (10 mg) along with tablet ciprofloxacin $(500 \mathrm{mg})$ one night prior to biopsy. Post-biopsy, oral antibiotics were continued for three days. Majority of the patients received local anaesthesia with either intrarectal instillation of $20 \mathrm{~mL}$ of $2 \%$ lignocaine jelly or periprostatic needle infiltration of local anaesthesia.

The findings on TRUS were documented for both the right and left lobe as follows: the presence of hypoechoic areas and/or calcifications in the periphery and the centre of the glands as well as the presence of capsular distortion. The prostate gland was assessed in the axial plane where the transverse and antero-posterior measurements were taken at the point of maximum diameter, followed by a paramedian longitudinal measurement in the sagittal plane.

The volume was calculated using a standard pre-programmed formula $\{\pi / 6 \times$ (transverse diameter) $\times$ (antero-posterior diameter) $\times$ (superior-inferior diameter)\} based on an ellipsoid shape.

The biopsies were taken using $17 \mathrm{~mm}$ tip Bard biopsy gun and sent for histopathological examination and reports were duly collected.

\section{STATISTICAL ANALYSIS:}

The data were compiled with the help of Microsoft Excel® application and statistical analysis was performed by a biostatistician. SPSS-28 statistical software was used to calculate the sensitivity, specificity, positive predictive value, negative predictive value and receiver operating characteristic curve was plotted to find the optimal cut-off value. The age, prostate size and grey zone PSA levels between benign and malignant disease patients were compared using Mann-Whitney test. A p-value less than 0.05 was considered to be significant.

\section{Results:}

A total of 125 patients were included in the study. 21 patients were diagnosed with carcinoma prostate. 
Table 1

Demography and PSA, TRUS and Biopsy correlation in our study.

\begin{tabular}{|c|c|c|c|c|}
\hline Observation & All Patients & Malignant Disease & Benign Disease & $\begin{array}{l}\text { p- } \\
\text { value }\end{array}$ \\
\hline Total patients & 125 & 21 & 104 & - \\
\hline Age (years) & $65(48-90)$ & $64.5(45-80)$ & $65(48-90)$ & $>0.05$ \\
\hline Prostate Size (grams) & $55.16(25-110)$ & $43.38(25-70)$ & $57.40(35-110)$ & $\begin{array}{l}< \\
0.001\end{array}$ \\
\hline $\begin{array}{l}\text { Total PSA }(\mathrm{ng} / \mathrm{mL}) \\
\text { (median) }\end{array}$ & $\begin{array}{l}09.67(4.2- \\
19.59)\end{array}$ & $\begin{array}{l}15.05(9.41- \\
19.59)\end{array}$ & $\begin{array}{l}7.715(4.2- \\
18.57)\end{array}$ & $>0.05$ \\
\hline
\end{tabular}

Mean age of the study participants was $66 \pm 8.9$ with minimum age 48 and maximum age 90 years. There was no significant difference in the age group of patients with benign and malignant disease. Patients with malignant disease had significantly smaller prostate gland size than patients with benign disease (40 vs 50; $p=<0.001$ ) [Table 1]. The sensitivity, specificity, positive predictive value and negative predictive value of TRUS guided biopsy are $75 \%, 95 \%, 98 \%$ and $100 \%$ respectively in our study. The number of PCa in category A, B, C, and D were $0,0,1$ and 26[Figure 1]. The overall cancer detection rate of TRUS biopsy in our series was $18.4 \%$. Out of 79 patients in the grey zone $(4-10 \mathrm{ng} / \mathrm{mL})$, only one patient had malignancy. The cancer detection rate in the grey zone $(4-10 \mathrm{ng} / \mathrm{ml})$ was $1.27 \%$. The overall cancer detection rate of TRUS biopsy in our series was $18.4 \%$. The cancer detection rates in groups $A, B, C$, and D were found to be $0 \%, 0 \%, 4.76 \%$, and $43.47 \%$ respectively [Table 2], implying that $49.43 \%$ of the patients underwent unnecessary biopsy in our study. The PSA cut-off to do biopsy was derived by ROC curve as $8.9 \mathrm{ng} / \mathrm{ml}$ for all men [Figure 2].

Table 2

- The Cancer detection rate in each category of our study.

\begin{tabular}{|llllll|}
\hline GROUP & $\begin{array}{l}\text { PSA range } \\
\text { (ng/mL) }\end{array}$ & $\begin{array}{l}\text { Total } \\
\text { patients }\end{array}$ & Benign & $\begin{array}{l}\text { Cancer } \\
\text { Prostate }\end{array}$ & $\begin{array}{l}\text { Cancer Detection Rate } \\
\text { (Percent) }\end{array}$ \\
\hline A & 4 to 6 & 35 & 35 & - & - \\
\hline B & 6 to 8 & 23 & 23 & - & - \\
\hline C & 8 to 10 & 21 & 20 & 1 & $4.76 \%$ \\
\hline D & 10 to 20 & 46 & 26 & 20 & $43.47 \%$ \\
\hline
\end{tabular}

\section{Discussion:}

The highest incidence of PCa is reported in Australia/New Zealand, Northern \& Western Europe and North America (79.8-111.6 per $1,00,000$ population) ${ }^{3}$. In Africa (10.6-61.7 per $1,00,000$ population), the southern African nations have higher incidence of PCa than north African nations, with highest incidence reported in Nigeria ${ }^{3}$. Among Asian countries (4.5-10.5 per 1,00,000 population), the incidence varies with 
lowest rates being in Iran and highest rates in Philippines ${ }^{3}$, with India falling in-between the two extremes ${ }^{4}$. The incidence of PCa in India has been reported to be ranging between 2 and 11.1 per $1,00,000$ population in various population-based cancer registries all over India ${ }^{5}$.

Our study shows low positive predictive value for PCa in the grey zone range (4-10) ng/mL of serum PSA. Our study proves that patients can be counselled and reassured regarding higher probability of benign outcome at serum PSA range (4-10) $\mathrm{ng} / \mathrm{mL}$.

Major studies conducted in India analysed the PSA levels between grey zone and PSA levels above 10 $\mathrm{ng} / \mathrm{mL}$. Agnihotri et al., had an overall cancer detection rate of $34.6 \%$ and for serum PSA ranges of (410) was $15.2 \%$ irrespective of DRE findings ${ }^{6}$. They had suggested raising the serum PSA cut off in symptomatic men with negative DRE for TRUS biopsy in India to $5.4 \mathrm{ng} / \mathrm{mL}$ to avoid $10 \%$ unnecessary biopsies. Agarwal et al., had a overall cancer detection rate of $34.6 \%$ with $28.3 \%$ detection rate in the grey zone levels. They suggested an increased sensitivity and specificity of biopsy yield for a cut off of 6 $\mathrm{ng} / \mathrm{mL}^{7}$. Chavan et al., had an overall cancer detection rate of $8.7 \%$ with $2.3 \%$ detection rate in the grey zone levels. Furthermore, they suggested raising the cut-off level to $20 \mathrm{ng} / \mathrm{mL}$ in Indian population for biopsy ${ }^{9}$. These reports reflect the low cancer detection rates of TRUS biopsy in grey zone PSA levels in Indian population which correlates with our study. In our study we have further stratified the grey zone levels into 4 categories and analysed each category statistically.

Many studies from other countries all over Asia have reported wide variations in the TRUS biopsy yield. Yu et al., from Taiwan a cancer detection rate of $14.6 \%$ in patients with serum PSA between (4.1-20) $\mathrm{ng} / \mathrm{mL}^{9}$. Narayanaswamy et al., from Kuwait reported lower yield for serum PSA ranges of (4-10) and $(10-20) \mathrm{ng} / \mathrm{mL}^{10}$.

A large retrospective study from China by $\mathrm{Na} R$ et al., reported lower yield for patients with serum PSA less than $10 \mathrm{ng} / \mathrm{mL}$ and (10-20) $\mathrm{ng} / \mathrm{mL}$ despite overall high yield ${ }^{11}$. Two studies from Singapore by Lee et al., and Teo et al., confirmed the lower yield for serum PSA below $10 \mathrm{ng} / \mathrm{mL}$ which was less than $21 \%$ 12,13. In contrast to other Asian studies, the study by Lee et al., reported higher yield of $38.4 \%$ for serum PSA range of (10-20) ng/mL ${ }^{12}$. Another large study by Teoh et al., from Hong Kong reported lower yield for symptomatic men with normal DRE with serum PSA below $20 \mathrm{ng} / \mathrm{mL}(22 \%)^{14}$. Two studies from Japan by Miyoshi et al., and Imazu et al., were the only studies from Asia showing much higher TRUS biopsy yield in contrast to all other Asian studies ${ }^{15,16}$.

The European studies showed much higher yield of TRUS biopsy as compared to Asian studies. Two studies from North America showed high TRUS biopsy yield more than $35 \%$. The largest study was reported by Orozco et al., from the Unites States, showing higher overall yield despite performing 6-core biopsies $^{17}$.

Hence, other than few exceptions, Asian population (including India) have a lower TRUS biopsy yield as compared to other continents, especially for serum PSA values less than $20 \mathrm{ng} / \mathrm{mL}$. Our study has 
confirmed the above findings. Hence the traditional serum PSA cut off of $4 \mathrm{ng} / \mathrm{mL}$ followed in western countries gives lower TRUS biopsy yield for Indian population. The current cut offs for PSA have high sensitivity and low specificity. Hence adjusting or raising the serum PSA cut offs for Indian population can increase the TRUS biopsy yield without increasing the false negative rate, thus avoiding unnecessary biopsies. Our study has a very low rate of post-biopsy complications requiring admission indicating that the procedure is safe if performed with accurate technique under antibiotic cover.

\section{Limitations:}

The limitation of our study is that repeat biopsies were not done in patients with high serum PSA and had negative initial biopsy. Also, all the patients with serum PSA below $4 \mathrm{ng} / \mathrm{mL}$ were not subjected to TRUS biopsy.

\section{Conclusion:}

Currently, a single demarcation between normal and elevated PSA values, $4.0 \mathrm{ng} / \mathrm{mL}$, is used as an indication for biopsy among men of all ages in the Indian population. Our study concludes that using the PSA cut-off value of $4 \mathrm{ng} / \mathrm{mL}$ derived from western literature has a lower positive predictive value in the Indian population as compared to western counterparts. Hence, we recommend that the cut-off be raised to $8.9 \mathrm{ng} / \mathrm{mL}$ to curb the burden of unnecessary TRUS guided biopsies in the Indian population.

\section{Declarations}

Ethical approval has been obtained from the Institutional ethical committee, Stanley medical college. We also declare that there are no competing interests.

\section{Abbreviations}

TRUS

Trans-rectal ultrasonography

PSA

Prostate specific antigen

$\mathrm{PCa}$

Prostate cancer

$\mathrm{ng} / \mathrm{mL}$

nanogram per millilitres

$\mathrm{MHz}$

Mega Hertz

$\mathrm{mm}$

milimetres

DRE 


\section{References}

1. Ferlay, J., et al. Cancer incidence and mortality worldwide: sources, methods and major patterns in GLOBOCAN 2012. Int J Cancer, 2015. 136: E359. https://pubmed.ncbi.nlm.nih.gov/25220842

2. MOSPI. 2016 66. Situat Anal Elder Pers India. Published online 2016.

3. Torre LA, Bray F, Siegel RL, Ferlay J, Lortet-Tieulent J, Jemal A. Global cancer statistics, 2012. CA Cancer J Clin. 2015;65(2):87-108.

4. Ferlay, J., et al. Cancer incidence and mortality worldwide: sources, methods and major patterns in GLOBOCAN 2012. Int J Cancer, 2015. 136: E359.

5. Hariharan K, Padmanabha V. Demography and disease characteristics of prostate cancer in India. Indian J Urol. 2016;32:103-08.

6. Jain S, Saxena S, Kumar A. Epidemiology of prostate cancer in India. Meta Gene. 2014;2:596-605.

7. Agnihotri S, Mittal RD, Kapoor R, Mandhani A. Raising cut-off value of prostate specific antigen (PSA) for biopsy in symptomatic men in India to reduce unnecessary biopsy. Indian J Med Res. 2014;139(JUN):851-856.

8. Agarwal MS, Sinha S, Juyal S, Gupta A K. Measurement of serum PSA in benign and malignant enlargements of prostate in Indian population: Relevance of PSAD in intermediate range PSA. Indian J Urol 2004;20:138-43

9. Chavan P R, Chavan S V, Chavan N R, Trivedi V D. Detection rate of prostate cancer using prostate specific antigen in patients presenting with lower urinary tract symptoms: A retrospective study. $\mathrm{J}$ Postgrad Med 2009;55:17-21

10. Yu HJ, Lai MK. The usefulness of Prostate-Specific Antigen (PSA) density in patients with intermediate serum PSA level in a country with low incidence of prostate cancer. Urology. 1998;51(5A Suppl):125-30

11. Narayanaswamy A, Abul F, Mathew TC. Detection rate and clinical pattern of prostate cancer in Kuwait: a single-center experience. Med Princ Pract. 2011;20(1):34-38.

12. Na R, Jiang H, Kim ST, Wu Y, Tong S, Zhang L, et al. Outcomes and trends of prostate biopsy for prostate cancer in Chinese men from 2003 to 2011. PLoS One. 2012;7(11):e49914. doi:

10.1371/journal.pone.0049914

13. Lee A, Chia SJ. Contemporary outcomes in the detection of prostate cancer using transrectal ultrasound-guided 12-core biopsy in Singaporean men with elevated prostate specific antigen and/or abnormal digital rectal examination. Asian Journal of Urology. 2015;2(4):187-93.

14. Teo JK, Poh BK, Ng FC, Fong YK. Detection rate of prostate cancer on the basis of the vienna nomogram: a Singapore study. Korean J Urol. 2014;55(4):245-48.

15. Teoh JY, Yuen SK, Tsu JH, Wong CK, Ho BSh, Ng AT, et al. Prostate cancer detection upon transrectal ultrasound-guided biopsy in relation to digital rectal examination and prostate-specific antigen level: 
what to expect in the Chinese population?. Asian J Androl. 2015;17(5):821-25.

16. Miyoshi Y, Furuya M, Teranishi J, Noguchi K, Uemura H, Yokomizo Y, et al. Comparison of 12- and 16core prostate biopsy in japanese patients with serum prostate-specific antigen level of 4.0-20.0 ng/mL. Urol J. 2014;11(3):1609-14.

17. Imazu T, Yokoyama S, Fukuhara S, Hara T, Yamaguchi S, Adachi S. [Analysis of transrectal needle biopsy of the prostate: usefulness of systematic 12 core biopsy]. Hinyokika Kiyo. 2007;53(6):36568.

18. Orozco R, O'Dowd G, Kunnel B, Miller MC, Veltri RW. Observations on pathology trends in 62,537 prostate biopsies obtained from urology private practices in the United States. Urology. 1998;51(2):186-95.

\section{Figures}

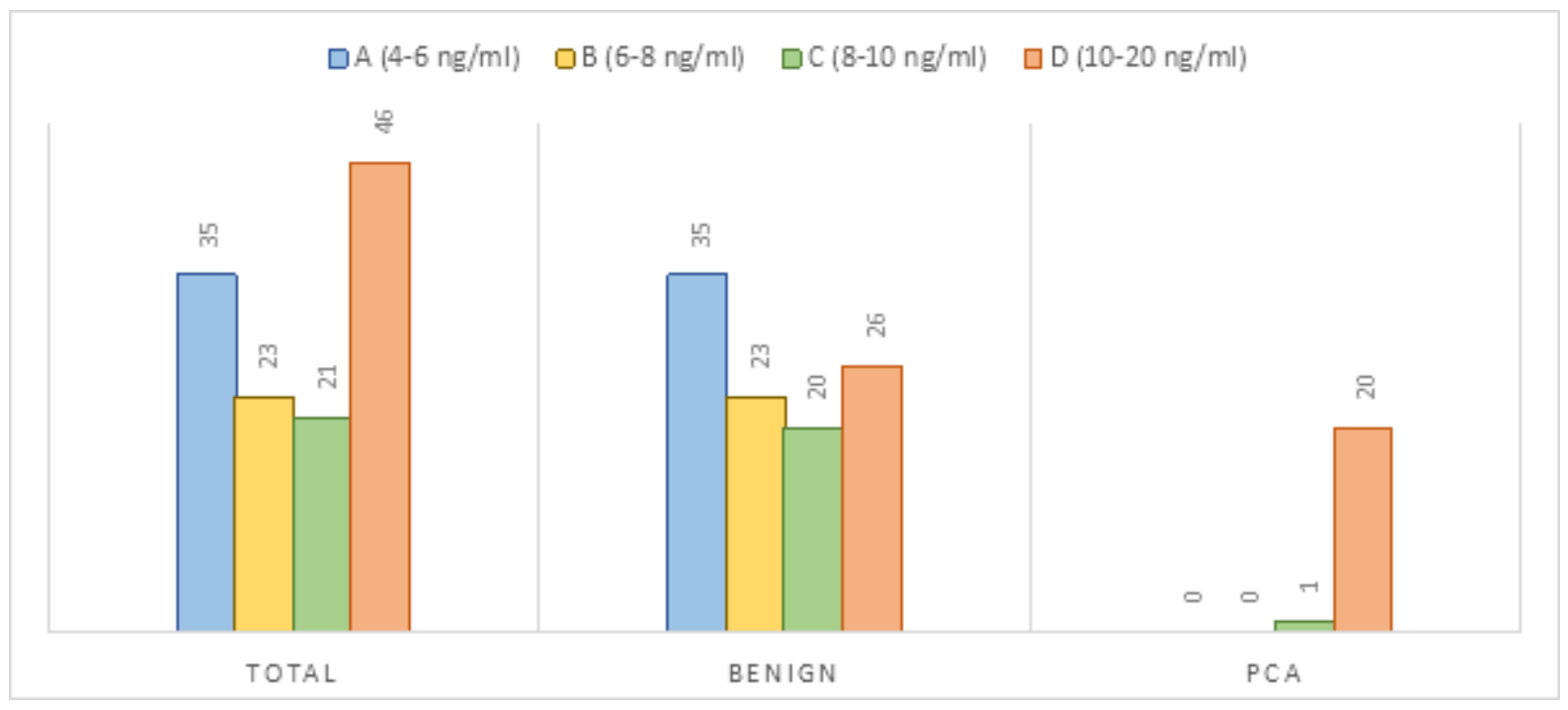

\section{Figure 1}

The incidence of benign and PCa in each category of PSA levels 


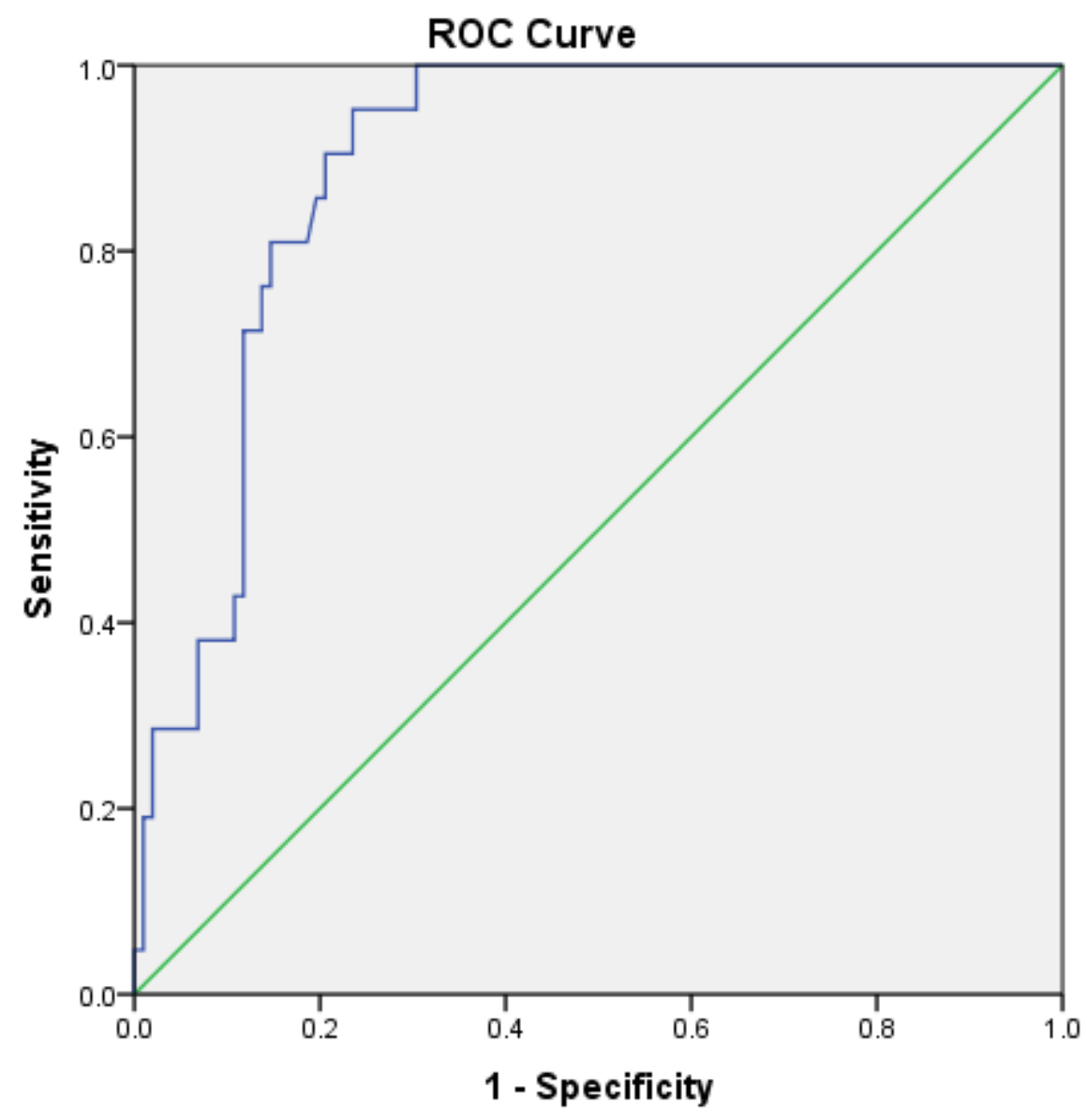

Diagonal segments are produced by ties.

Figure 2

PSA cut-off of $8.9 \mathrm{ng} / \mathrm{ml}$ derived from ROC curve 